\title{
University Students’ Acceptance of Evolution: Basis for STEM-based Instructional Design
}

Submitted 1 June 2021, Revised 19 July 2021, Accepted 31 July 2021

\author{
Odessa D Aberilla ${ }^{*}$, Monera H Salic ${ }^{1}$, Ronaldo R. Orbita ${ }^{2}$, Joy B. Bagaloyos ${ }^{3}$, Cesar G. Demayo ${ }^{4}$, \\ Mark Anthony G. Torres ${ }^{4}$, \\ ${ }^{1}$ Department of Science and Mathematics Education, College of Education, \\ MSU-Iligan Institute of Technology, Iligan City, Philippines \\ ${ }^{2}$ Department of Professional Education, College of Education, \\ MSU-Iligan Institute of Technology, Iligan City, Philippines \\ ${ }^{3}$ Integrated Developmental School, MSU-Iligan Institute of Technology, Iligan City, Philippines \\ ${ }^{4}$ Department of Biological Sciences, MSU-Iligan Institute of Technology, Iligan City, Philippines \\ Corresponding email: *odessa.aberilla@g.msuiit.edu.ph
}

\begin{abstract}
This study was conducted to explore the overall acceptance of evolution among undergraduate students in a State University as basis for developing a STEM-based instructional design to address the misconceptions about evolution. The research was conducted using the 20-item questionnaires of the Measurement of Acceptance of the Theory of Evolution (MATE) instrument assessing undergraduate students' acceptance of evolution in relations to; the process of evolution, the scientific validity of the evolutionary theory, the evolution of humans, evidence of evolution, scientific community's view of evolution and age of the Earth. The study is within a quantitative and qualitative framework using descriptive and inferential analysis. The findings revealed that all the colleges in the science group acquired a moderate level of acceptance except for the CED non-science group who received a low degree of acceptance of the theory of evolution. Although among the six concepts in the study, they generally agree on the statements and only in the idea on the age of the earth where the students were undecided. This research confirms that the level of acceptance is not positively related to the students' specialization. Based on the result of this study there is a need to develop a STEM based instructional design and this should be emphasized in the science curriculum. The teaching design will fill in the gaps in understanding concepts of evolution and its significance to the lives of many organisms and for the teachers to look evolution from very broad flexible and interdisciplinary perspectives.
\end{abstract}

Keywords: undergraduate students' acceptance of evolution, STEM-based instructional design, STEM education

\section{INTRODUCTION}

Inquiry-based approach is the traditional strategy used in the classroom in teaching and understanding evolution theory. Developing student's understandings of evolution occurs when the teachers can distinguish the different perspectives in knowing the natural world. Learning evolution is important for students to acquire the process of scientific inquiry that is essential in making informed decisions and to increase the innovativeness and competitiveness in the $21^{\text {st }}$ century. Evolutionary theory is continuously advancing and developing (Hanisch \& Eirdosh, 2020) and with this development, a need to discover teaching strategies that will help the students grapple the demands in understanding the importance of evolution in their daily lives. There have been studies conducted about the acceptance and understanding of the theory of evolution among schools in the world. The students can never be considered blank slates, beginning with zero knowledge, yet there is often little time invested by instructors in finding out in depth what students already know and what they do not know, what they are confused 
about, and how their preconceptions about the world do or do not fit with new information they are attempting to learn (Tanner \& Allen, 2005). The performance of students may be attributed to students' personal experiences in their environment by giving them opportunity to construct new knowledge, and ideas (Orongan, et.al, 2019). Lack of students interest, aptitude and lack of facilities, equipment, etc., have been cited by teachers as primary or contributing factors in students' failure to be captivated by the study of biology (Scharmann, 1994).

One method of measuring the effectiveness of instruction in evolutionary biology is by assessing changes in student acceptance of, rather than belief in, evolutionary theory as a scientifically valid and explanatory theory (Rutledge \& Sadler). This may be mainly attributed to the fact that many misrepresent evolution and undermine the students' understanding of the subject because of what they have learned from their teachers. Understanding evolution gives impact on understanding our world and current issues which concerns genes, mutations, populations, sex living organisms, medical advances, agriculture, and other biological processes. Science teacher educators have attempted to address this issue through professional development opportunities focusing on content knowledge (Nehm, RH, \& Schonfeld, 2007).

In this study, we introduce some perspectives in order to come up with a broader sense of conceptualizations as it emerges from interdisciplinary strategies that may help learning difficulties turned into a disciplinary connections that may provide more learning opportunities using STEM-based teaching strategies. Understanding the process of evolution is important to science education because it will help the future educators to explain the scientific facts versus the conceptions and misconceptions. Many freshman biology students can recite facts about evolution, but their understanding of the principles and applications of evolution are minimal (Jensen \& Finley, 1997). Teachers teaching science education need to distinguish appropriate teaching tools, programs, instructional materials that can support student's understanding in evolution. The theory of evolution is foundational to the study of biology (American Association for the Advancement of Science, 1993) and forms a critical component of scientific literacy for all ages (Brewer \& Smith, 2011).

This study aimed to explore the level of acceptance of the theory of evolution, and to determine if there is a need to develop a STEM-based instructional design specifically in teaching evolution. This research sought to answer the following questions:

1. What is the overall acceptance between the science and non-science undergraduate students in terms of scientific validity of evolutionary theory, evolution of humans, evidences of evolution, scientific community's view of evolution, and the age of the earth; and 
2. What are the suggested STEM-based instructional and teaching designs in teaching evolution?

The result of this study will indicate the student's acceptance and will guide the researcher on the possibilities of applying STEM-based instructions in teaching the theory of evolution.

\section{METHOD}

The methods and procedures of this study include the respondents/subjects of the study, the research design, instruments used and the data gathering procedure. The respondents of this study were undergraduate students in a State University in Mindanao, Philippines, who were officially enrolled during the first semester and second semester of the academic year 20182019 from all colleges / programs at different levels (senior high to fourth year level) and specializations ( science and non-science majors). Each respondents remained anonymous with no personal names collected.

The study utilized a quantitative approach in examining the data. The date gathered were analyzed using descriptive and inferential analysis statistics. The dependent variable was considered based on their college and specialization. This study was carried through a survey method using the Measurement of Acceptance of the Theory of Evolution (MATE) questionnaire which were already validated from (Rutledge and Sadler, 2007) study.

The MATE instrument utilized in the study was used to assess or measure the level of acceptance and degree of understanding of the theory of evolution in the concepts; process of evolution, scientific validity of evolutionary theory, evolution of humans, evidence of evolution, scientific community's view of evolution, and the age of the earth (Rutledge and Sadler, 2007). The MATE is a 20-item Likert-scale evolution acceptance questionnaire with a high value of reliability Cronbach alpha coefficient of 0.98 based on the report of Rutledge and Warden (1999).

The survey instrument was distributed across all programs of the iuniversity. The respondents were asked to answer the adapted survey questionnaire from Rutledge and Sadler. The respondents answered according to the 6 concepts namely: (I) process of evolution; (II) scientific validity; (III) evolution of Humans; (IV) evidence of evolution; (V) scientific community views; and (VI) age of the earth. Each of the categories have specific accounts of which the students have to answer strongly agree (SA); agree (A); undecided (U); disagree (D); and strongly disagree (SD). The respondents were asked to answer on how they understand each concept according to their practices and experiences. Survey questionnaires are then 
collected and submitted for data analysis and interpretation. The information of the respondents are then kept confidential.

\section{RESULTS AND DISCUSSION}

A total of 826 responses for the full survey and of these $72 \%$ were science majors and $28 \%$ non-science major. Most of the science majors were biology majors, chemistry, general science, health sciences, and science, technology, engineering, and math (STEM). Most of the non-science majors were from English, Filipino, entrepreneurial marketing, engineering, education program and information systems. Seventy-seven percent of students were Christians, $19 \%$ Islam, and $4 \%$ were agnostic or atheist. The overall response rate was $82 \%$. A total of 1000 survey questionnaire were unevenly distributed between different colleges and disciplines and only 826 were returned and answered. Respondents were grouped according to science $(n=593)$ and non-science $(n=233)$ group. The difference in the number of respondents does not directly affect the result of this study.

Table 1. Level of acceptance between science and non-science students.

\begin{tabular}{|c|c|c|c|c|c|c|c|c|}
\hline College & $\begin{array}{l}\text { Process of } \\
\text { Evolution }\end{array}$ & $\begin{array}{l}\text { Scientific } \\
\text { Validity }\end{array}$ & $\begin{array}{c}\text { Evolution } \\
\text { of } \\
\text { Humans }\end{array}$ & $\begin{array}{c}\begin{array}{c}\text { Evidence } \\
\text { of } \\
\text { Evolution }\end{array} \\
\end{array}$ & $\begin{array}{c}\text { Scientific } \\
\text { community's } \\
\text { View }\end{array}$ & $\begin{array}{l}\text { Age of } \\
\text { the } \\
\text { Earth }\end{array}$ & $\begin{array}{l}\text { Overal } \\
\text { I Score }\end{array}$ & Remarks \\
\hline \multicolumn{9}{|l|}{ Science } \\
\hline $\mathrm{CED}^{1}$ & 14.28 & 20.20 & 6.81 & 12.18 & 6.31 & 7.40 & 67.18 & $\begin{array}{l}\text { Moderate } \\
\text { Acceptance }\end{array}$ \\
\hline $\mathrm{IDS}^{2}$ & 15.03 & 20.89 & 7.14 & 13.03 & 7.04 & 7.90 & 71.03 & $\begin{array}{l}\text { Moderate } \\
\text { Acceptance }\end{array}$ \\
\hline $\mathrm{CON}^{3}$ & 15.36 & 22.38 & 7.47 & 14.96 & 7.13 & 7.51 & 74.80 & $\begin{array}{l}\text { Moderate } \\
\text { Acceptance }\end{array}$ \\
\hline $\mathrm{CSM}^{4}$ & 15.38 & 22.05 & 7.19 & 14.37 & 7.13 & 7.70 & 73.81 & $\begin{array}{l}\text { Moderate } \\
\text { Acceptance }\end{array}$ \\
\hline Mean & 15.01 & 21.38 & 7.15 & 13.63 & 6.90 & 7.63 & 71.71 & $\begin{array}{l}\text { Moderate } \\
\text { Acceptance }\end{array}$ \\
\hline \multicolumn{9}{|c|}{ Non-science } \\
\hline $\mathrm{CASS}^{5}$ & 14.47 & 21.49 & 6.66 & 13.68 & 7.02 & 7.53 & 70.85 & $\begin{array}{l}\text { Moderate } \\
\text { Acceptance }\end{array}$ \\
\hline $\mathrm{CBAA}^{6}$ & 13.41 & 19.82 & 6.25 & 12.61 & 6.41 & 7.05 & 65.54 & $\begin{array}{l}\text { Moderate } \\
\text { Acceptance }\end{array}$ \\
\hline $\mathrm{CCS}^{7}$ & 12.80 & 19.11 & 5.82 & 12.10 & 6.22 & 7.14 & 63.19 & $\begin{array}{l}\text { Low } \\
\text { Acceptance }\end{array}$ \\
\hline $\mathrm{CED}^{8}$ & 12.97 & 19.51 & 5.86 & 11.29 & 6.53 & 6.57 & 62.73 & $\begin{array}{l}\text { Low } \\
\text { Acceptance }\end{array}$ \\
\hline $\mathrm{COET}^{9}$ & 12.90 & 18.15 & 5.90 & 12.46 & 6.49 & 7.20 & 63.10 & $\begin{array}{l}\text { Low } \\
\text { Acceptance }\end{array}$ \\
\hline Mean & 13.31 & 19.62 & 6.10 & 12.43 & 6.54 & 7.10 & 65.08 & $\begin{array}{l}\text { Moderate } \\
\text { Acceptance }\end{array}$ \\
\hline
\end{tabular}

${ }^{1}$ College of Education science majors, ${ }^{2}$ Integrated Developmental School STEM strand, ${ }^{3}$ College of Nursing, ${ }^{4}$ College of Science and Mathematics, ${ }^{5}$ College of Arts and Social Sciences, ${ }^{6}$ College of Business Administration and Accountancy, ${ }^{7}$ College of Computer Studies, ${ }^{8}$ College of Education non-science majors, ${ }^{9}$ College of Engineering and Technology

In the overall acceptance of evolution, the data compares the level of acceptance of science and non-science major students on the idea of organic evolution. Results show that the 
overall percentage scores across colleges vary from $62.73 \%$ to $74.80 \%$. This score range is only within the low to moderate acceptance. Among the colleges, students from the College of Nursing (74.80\%) ranked first place followed by those from the College of Science and Mathematics (73.81\%), then Integrated Development School (71.03\%). Students from the College of Science and Mathematics scored only $73.81 \%$, which is still classified as moderate acceptance. Lowest percentage scores were garnered by non-science majors coming from the College of Computer Science (63.19\%), College of Engineering and Technology (63.1\%), and College of Education (62.73\%). The overall acceptance scores between science and nonscience majors are $71.71 .49 \%$ and $65.08 \%$, respectively. This means that science majors registered higher affirmative responses to the issue of organic evolution. However, the difference is only at a few points between the two. Still, the qualitative description is moderate acceptance for science and non-science majors.

Science majors are likely to register positive responses compared to the non-science majors because of their exposure to biology subjects in their present curriculum. Nevertheless, it does not mean that non-science majors do not have prior knowledge in biological science because during the early education years, biological science has been part of the K-12 science curriculum. Majority of the colleges are in moderate acceptance. This means that they did not generally disagree or agree on the concept but they are doubtful of the concept which made them choose undecided in the level of agreement. In this case, misconceptions tend to be the aspect of their moderate level of acceptance. Though, there are many factors to be considered in the level of acceptance, some of the indicators for the low level of acceptance include limited education, income, political orientation, and religious commitment (Nadelson\& Hardy 2015). The result can also be attributed to socio-cultural factors such as the nature of religion and the influence of teaching biology (Athanasiou \& Papdopoulou, 2012). This low acceptance of evolution is often related to a high acceptance of Creationism in various forms like Intelligent Design (Kampourakis, 2014) or hold high levels of religiosity and low trust in science (Nadelson \& Hardy, 2015).

The reason of the low to moderate acceptance of evolution of the students' might be because one of the five factors presented by Alters \& Nelson (2002) also they believed that five types of misconceptions and mistaken assumptions are the following; (1) From-experience misconceptions (are those that students surmise from their everyday experiences); (2) selfconstructed misconceptions (occur when information that student see or hear conflicts with what they already "know" but, rather than change their misconception, they accommodate the new knowledge in the framework of an old misconception); (3) taught-and-learned 
International Journal of STEM Education for Sustainability, Vol.1, No.1, 2021, pp. 33-44

e-ISSN 2798-5091. DOI. 10.53889/ijses.v1i1.3

misconceptions (are unscientific facts that have been taught informally by parents and others or unconsciously learned from fiction); (4) vernacular misconceptions (arise from the difference between the scientific use of a word and its everyday use, and the consequent misunderstanding of the distinction); and (5) Religious and myth-based misconceptions (are concepts in religious and mythical teachings that, when transferred into science education, become factually inaccurate). The result show surprisingly that only a little difference in the rating between science and non-science majors. Both majors already undergone elementary biology or let us say basic biology, certainly, fundamental science concepts are often "taught" but not learned (Alters and Nelson, 2002).

In the overall degree of acceptance according to its concept, results show that more than $80 \%$ of the students either strongly agree or agree on the idea that extant organisms are the results of long history of evolution which occurred millions of years. This process also explains phenotypic diversity in organisms, whether behavioral or morphological, which is a belief shared by $75 \%$ of the students. The overall affirmative response to belief in the process of evolution is $53.8 \%$, while those who do not accept the idea comprises $27.1 \%$ of the study population.

With regards to the scientific validity of the theory of evolution, less than half of the respondents believed that it has a sound scientific backing (44.3\%). There seems to be dissonance in the answers as provided by the students. This is because while a significant majority think that current evolutionary theory is the result of sound scientific research and methodology $(65.9 \%)$, more than half $(55.6 \%)$ posit that evolution is not a scientifically valid theory. On the evolution of humans, sixty eight percent (68\%) gave affirmative answers stating that extant humans are product of long history of adaptation and selection. Only minor percentage believe that humans today have not changed in morphology through time $(45.8 \%)$. Just pass half the total study population believe that evidences exist to support the idea of evolution. These includes factual and historical data (67.1\%) and other sources (62.6\%).

Nearly three-fourth $(74 \%)$ of the total respondents believe that the scientific community, at least at the local setting, believe in the phenomenon of biological evolution. This number seems to be big enough to show support to the theory of evolution, however, twenty-three percent (23.9\%) believe otherwise. This percentage is worrisome as this does not represent the opinion of the general public but people from the academe who are supposed to teach science.

In support to the idea of biological evolution, fifty-nine percent (59\%) of the students accept the idea that the Earth is at least 4 Billion years old. On the other hand, 35\% do not agree with 
this. This means that majority believe that the age of the earth as a plant in the solar system is at least 4 Billion years old.

The overall result showed that the level of acceptance of the theory of evolution among the undergraduate students in MSU-IIT is affirmative with $80 \%$ acceptance of evolution. In 2006 a study was conducted in the Philippines revealed that $62.16 \%$ accept evolution and thirteen percent (13.51\%) were doubtful of evolution (Clores \& Limjap, 2006).

The science group and non-science group are more likely have the same level of acceptance. Evidently science group have greater knowledge in terms of exposure to science because of the biology subjects in their curriculum. The non-science group also have background in science during their high school education similarly with the science group. Positively, both groups have prior knowledge of evolution. student's acceptance of evolution is the result of the prior knowledge the students have in their prior education. Religiosity and political orientation are also predictors of acceptance of biological evolution (Nadelson \& Hardy, 2015).

New theoretical considerations based on new methods and empirical findings are being added over the years and decades into a more nuanced understanding of how evolution operates across the biological world and beyond (Hanisch \& Eirdosh, 2020). There are misconceptions about evolution which needs clarification and appropriate teaching tools. Being aware of inaccurate preconceptions can help the teachers respond to student queries appropriately, avoid reinforcing such misconceptions, and develop instructional materials and strategies that correct these ideas (University of California Museum of Paleontology , 2008).

This research confirms that the level of acceptance is not positively related to the students' specialization and also with the degree of understanding of the concepts. The overall acceptance of the science and non-science major students shows an overall percentage scores which varies from $62.73 \%$ to $76.75 \%$ as shown in table 1 , which range is only within the low to moderate acceptance. It was presumed that the science major students will have a greater range of acceptance compared to the non-science major students because of their exposure and prior knowledge in biology.

Among the eight (8) programs the students of the College of Nursing revealed the highest level of acceptance in terms of the overall rating of 74.80 points. Some reasons might be considered of their high acceptance as compared to other science related courses; first, might be because of the students' exposure to the hospital setting where they discuss concepts like multi-drug resistance; and secondly, the college of nursing curriculum are mostly health and life sciences. The exposure of the students are not only limited in the classroom but also outside 
the classroom. Students' acceptance of evolution is therefore possibly strengthened by the measure of exposure they have had to teachers and lecturers who teach evolution as an integral part of the discipline, irrespective of the level of knowledge of evolution concepts (Coleman et al., 2015).

In this table, shows the overall degree of acceptance per concept. With the results, the teachers can design STEM instructional materials based on the concepts presented. The data shows on what specific concept the students lack understanding based on the responses.

Table 2. Percentage distribution of responses from the students

\begin{tabular}{|c|c|c|c|c|c|}
\hline & $\mathbf{S A}$ & $\mathbf{A}$ & $\mathbf{U}$ & $\mathbf{D}$ & SD \\
\hline \multicolumn{6}{|l|}{ I. Process of Evolution } \\
\hline $\begin{array}{l}\text { Organisms existing today are the result of an evolutionary } \\
\text { process that has occurred over millions of years. }\end{array}$ & $41.8 \%$ & $40.7 \%$ & $9.4 \%$ & $4.2 \%$ & $3.9 \%$ \\
\hline $\begin{array}{l}\text { Organisms exist today in essentially the same form in } \\
\text { which they always have. }\end{array}$ & $3.9 \%$ & $20.1 \%$ & $19.2 \%$ & $39.2 \%$ & $17.6 \%$ \\
\hline $\begin{array}{l}\text { The theory of evolution brings meaning to the diverse } \\
\text { characteristics and behaviors observed in living forms. }\end{array}$ & $20.5 \%$ & $55.1 \%$ & $18.8 \%$ & $4.8 \%$ & $0.8 \%$ \\
\hline $\begin{array}{l}\text { With few exceptions, organisms on earth came into } \\
\text { existence at about the same time. }\end{array}$ & $7.0 \%$ & $26.3 \%$ & $29.1 \%$ & $24.8 \%$ & $12.8 \%$ \\
\hline Mean & $18.3 \%$ & $35.5 \%$ & $19.1 \%$ & $18.3 \%$ & $8.8 \%$ \\
\hline \multicolumn{6}{|l|}{ II. Scientific Validity } \\
\hline $\begin{array}{l}\text { The theory of evolution is incapable of being scientifically } \\
\text { tested. }\end{array}$ & $5.7 \%$ & $23.6 \%$ & $31.4 \%$ & $29.5 \%$ & $9.8 \%$ \\
\hline Evolution is not a scientifically valid theory. & $2.4 \%$ & $15.6 \%$ & $26.4 \%$ & $38.3 \%$ & $17.3 \%$ \\
\hline $\begin{array}{l}\text { Current evolutionary theory is the result of sound scientific } \\
\text { research and methodology. }\end{array}$ & $11.4 \%$ & $54.5 \%$ & $25.9 \%$ & $7.3 \%$ & $1.0 \%$ \\
\hline $\begin{array}{l}\text { Evolutionary theory generates testable predictions with } \\
\text { respect to the characteristics of life. }\end{array}$ & $10.5 \%$ & $56.1 \%$ & $25.8 \%$ & $6.8 \%$ & $0.8 \%$ \\
\hline $\begin{array}{l}\text { The theory of evolution cannot be correct since it disagrees } \\
\text { with Biblical account of creation. }\end{array}$ & $7.5 \%$ & $18.5 \%$ & $33.4 \%$ & $26.9 \%$ & $13.7 \%$ \\
\hline \multirow[t]{2}{*}{ Evolution is scientifically valid theory. } & $17.8 \%$ & $42.3 \%$ & $28.6 \%$ & $9.7 \%$ & $1.7 \%$ \\
\hline & $9.2 \%$ & $35.1 \%$ & $28.6 \%$ & $19.7 \%$ & $7.4 \%$ \\
\hline \multicolumn{6}{|l|}{ III. Evolution of Humans } \\
\hline $\begin{array}{l}\text { Modern humans are the product of evolutionary processes } \\
\text { that have occurred over millions of years. }\end{array}$ & $26.5 \%$ & $42.0 \%$ & $13.8 \%$ & $10.0 \%$ & $7.6 \%$ \\
\hline $\begin{array}{l}\text { Humans exist today in essentially the same form in which } \\
\text { they always have. }\end{array}$ & $9.6 \%$ & $26.9 \%$ & $17.8 \%$ & $31.6 \%$ & $14.2 \%$ \\
\hline Mean & $18.0 \%$ & $34.4 \%$ & $15.8 \%$ & $20.8 \%$ & $10.9 \%$ \\
\hline \multicolumn{6}{|l|}{ IV. Evidence of Evolution } \\
\hline $\begin{array}{l}\text { The theory of evolution is based on speculation and not } \\
\text { valid scientific observation and testing. }\end{array}$ & $7.6 \%$ & $26.5 \%$ & $25.3 \%$ & $26.9 \%$ & $13.7 \%$ \\
\hline $\begin{array}{l}\text { The available data are ambiguous as to whether evolution } \\
\text { occurs. }\end{array}$ & $5.9 \%$ & $34.6 \%$ & $28.0 \%$ & $25.2 \%$ & $6.3 \%$ \\
\hline $\begin{array}{l}\text { There is a significant body of data that supports } \\
\text { evolutionary theory. }\end{array}$ & $11.3 \%$ & $51.3 \%$ & $27.1 \%$ & $8.0 \%$ & $2.3 \%$ \\
\hline $\begin{array}{l}\text { Evolutionary theory is supported by factual historical and } \\
\text { laboratory data. }\end{array}$ & $14.3 \%$ & $52.8 \%$ & $22.0 \%$ & $10.2 \%$ & $0.7 \%$ \\
\hline Mean & $9.8 \%$ & $41.3 \%$ & $25.6 \%$ & $17.6 \%$ & $5.8 \%$ \\
\hline \multicolumn{6}{|l|}{ V. Scientific community views } \\
\hline $\begin{array}{l}\text { Most scientists accept evolutionary theory to be a } \\
\text { scientifically valid theory. }\end{array}$ & $14.6 \%$ & $59.4 \%$ & $19.9 \%$ & $5.2 \%$ & $0.8 \%$ \\
\hline $\begin{array}{l}\text { Much of the scientific community doubts if evolution } \\
\text { occurs. }\end{array}$ & $6.3 \%$ & $27.8 \%$ & $32.7 \%$ & $25.5 \%$ & $7.6 \%$ \\
\hline Mean & $10.5 \%$ & $43.6 \%$ & $26.3 \%$ & $15.4 \%$ & $8.5 \%$ \\
\hline
\end{tabular}


International Journal of STEM Education for Sustainability, Vol.1, No.1, 2021, pp. 33-44

e-ISSN 2798-5091. DOI. 10.53889/ijses.v1i1.3

The age of the Earth is less than 20,000 years.

The age of the Earth is at least 4 billion years.

\begin{tabular}{cccccc} 
& $2.9 \%$ & $6.5 \%$ & $29.5 \%$ & $23.2 \%$ & $37.7 \%$ \\
& $16.7 \%$ & $43.1 \%$ & $31.2 \%$ & $6.2 \%$ & $2.8 \%$ \\
Mean & $9.8 \%$ & $24.8 \%$ & $30.4 \%$ & $14.7 \%$ & $20.2 \%$ \\
\hline
\end{tabular}

$\overline{S A}=$ Strongly Agree; $A=$ Agree; $U=$ Undecided; $D=$ Disagree; $S D=$ Strongly Disagree

The data indicates that there is a need to introduce teaching and learning design which incorporates all aspects that will improve learning and understanding of the evolution concept. Recent studies introduced the new ways of integrating content and practices among technology, engineering, science, and mathematics which generates the principles to enhance the student learning of complex concepts (Sutaphan \& Yuenyong, 2018). The evolution education continues to be confronted with the persistent challenges to evolution understanding and acceptance (Hanisch \& Eirdosh, 2020).

The reasons of the low to moderate acceptance of the students maybe they lack knowledge of the concepts relevant to evolution. Student's lack of understanding of the natural selection may contribute to their lack of understanding of evolution (Coleman et al., 2015). We suggest that if we want our students to understand and accept evolution, a more realistic picture of the nature and process of science is essential (Lombrozo, Thanukos, \& Weisberg, 2008).

Based on the gathered data information, and the ideas shared by the expert Professors who teach evolution, Lesson Study and Inquiry-based science teaching method maybe an effective tool in teaching evolution. The challenge is to design diversified instructional materials and approaches to improve the competence in teaching evolutional and for the teachers to look evolution from a very broad flexible, and interdisciplinary perspectives. Teacher training is also suggested both in contents and methods because teachers plays critical roles as facilitators of learning. The researchers suggest a STEM-based instructional design an exploration of different strategies using STEM education teaching approaches such as: STEM education teacher training, STEM team teaching, exploration of new curriculum and methods for delivering STEM concepts in teaching evolution (Sutaphan \& Yuenyong, 2018).

The University of California Museum of Paleontology (UCMP) and the National Center for Science Education created a website on "Understanding Evolution" to support teaching and learning about foundational science content. One of the highlighted issues is the different misconceptions about evolution:

- Misconceptions about evolutionary theory and processes;

- Misconceptions about natural selection and adaptation;

- Misconceptions about evolutionary trees;

- Misconceptions about population genetics; 
- Misconceptions about evolution and the nature of science;

- Misconceptions about the acceptance of evolution;

- Misconceptions about the impact of evolution;

- Misconceptions about evolution and religion; and

- Misconceptions about teaching evolution

These are common misconceptions regarding evolution and many of these misconceptions are related to common teaching pitfalls (University of California Museum of Paleontology , 2008). Based on studies, teachers are a great contributor to the misconceptions of evolution. The misconceptions can be used as foundation in identifying appropriate teaching and learning activities using STEM-based approaches. For example distinguishing facts from beliefs or opinions is very important in understanding what is happening in the real world of science.

Learning and understanding the theory of evolution can be taught and learned using interdisciplinary approaches-- STEM. In addition, STEM teaching learning activities and ideas includes classes in science, mathematics, geography (Sutaphan \& Yuenyong, 2018), sustainability, linguistics, psychology, computer science, history (Hanisch \& Eirdosh, 2020) and other related fields. Evolution involves interdisciplinary conceptual understanding which requires interdisciplinary approaches. STEM-based teaching promotes cognitive and affective dimensions that are very essential in understanding the purpose of studying evolution. According to studies stem-based learning could improve cognitive and affective skills. The success in the modern era is determined by how students strive to have certain skills; and this can be achieved by students through the development of cognitive domain (Firdaus \& Rahayu, 2019)

In the study (Sutaphan \& Yuenyong, 2018) suggested some ideas of STEM teaching and learning and presented consensus issues of discussion about STEM education (a) instructionally; (b) as a set of integrated or interconnected disciplines; or (c) as more dependent on the stakeholders or context in which it is viewed or conceptualized. The ideas presented pictures out the broad component of the implementation of STEM in schools or universities envisioning to improve and adapt the challenges brought by the development and advancement of science and technology. The researchers take into consideration the implementation of STEM in teaching evolution to help students understand and accept the significant impact of evolution. 
International Journal of STEM Education for Sustainability, Vol.1, No.1, 2021, pp. 33-44

e-ISSN 2798-5091. DOI. 10.53889/ijses.v1i1.3

\section{CONCLUSIONS}

Based on the result of this study there is a need to develop a STEM-based instructional design and this should be emphasized in the science curriculum. However, applying STEM in teaching evolution requires thorough study and assessment on its effectiveness. A teaching design that will fill in the gaps in understanding concepts of evolution and its significance in the advancement of science, medical technology (understanding diseases, its cure) and to the academic society. The researchers suggested to conduct further study to have an in depth analysis on what is the appropriate and effective STEM-based instructional design be designed for the undergraduate students to both science and non-science majors.

\section{ACKNOWLEDGEMENT}

The authors would like to express its sincerest gratitude to the respondents of this study, and reviewers who ensure that this paper is worthy for publication.

\section{REFERENCES}

American Association for the Advancement of Science. (1993). Benchmarks for science literacy. Oxford University Press .

Athanasiou, K., \& Papdopoulou, P. (2012). Conceptual ecology of the evolutio acceptance among Greek education students: knowledge, religious practices and social influences. International Journal of Science Education.

Brewer, C., \& Smith, D. (2011). Vision and change in graduate undergradaute biology education: a call to action. American Association for the Advancement of Science .

Clores, M. A., \& Limjap, A. A. (2006, May). Diversity of Student's Belief about Biological Evolution. Asia Pacific Journal of Education , 65-77.

Firdaus, A. R., \& Rahayu, G. D. (2019). Effect of STEM-based learning on the Cognitive Skills Improvement. Mimbar Sekolah Dasar , 198-207.

Hanisch, S., \& Eirdosh, D. (2020). Educational potential of teaching evolution as an interdisciplinary science. Evolution: Education and Outreach .

Jensen, M. S., \& Finley, F. N. (1997). Teaching Evolution Using a Historically Rich Curriculum \& Paired Problem Solving Instructional Strategy. The American Biology Teacher, 59 (4).

Lombrozo, T., Thanukos, A., \& Weisberg, M. (2008). The Importance of Understanding the Nature of Science for Accepting Evolution. Evo Edu Outreach, 290-298.

Nehm, RH, \& Schonfeld, I. (2007). Does increasing biology teacher knowledge of evolution and the nature of science lead to greater preference for the teaching of evolution in schools? Journal of Science Teacher Education , 699-723. 
Rutledge , M. L., \& Sadler, K. C. (n.d.). Reliability of the Measurement of Acceptance of the Theory of Evolution (MATE) Instrument with University Students.

Scharmann, L. C. (1994). Teaching Evolution: Designing Successful Instruction. Journal of Science Teacher Education , 5 (4), 122-129.

Sutaphan, S., \& Yuenyong, C. (2018). STEM Education Teaching approach: Inquiry from the Context Based. Journal of Physics.

Tanner, K., \& Allen, D. (2005). Approaches to Biology Teaching and Learning: Understanding the Wrong Answers-Teaching toward Conceptual Change. Cell Biology Education , 4, 112-117.

University of California Museum of Paleontology . (2008, August 22). Understanding Evolution. Retrieved June 2021, from Understanding Evolution: http://evolution.berkeley.edu/ 